\title{
Da possibilidade de uma Teoria Pura da Ciência da Informação: reflexões iniciais entre a Ciência da Informação e a Ciência do Direito ${ }^{1}$
}

Max Cirino de Mattos

Graduado em Ciência da Computação (PUCMG).Especialista em Gestão em Informação Tecnológica (UFMG).MBA Executivo em Finanças (IBMEC-MG).Mestre e Doutorando em Ciência da Informação (UFMG)

Andityas Soares de Moura Costa Matos

Graduado em Direito. Mestre em Filosofia do Direito e Doutor em Direito e Justiça pela Faculdade de Direito da UFMG. Membro do Corpo Permanente do Programa de Pós-Graduação em Direito da Faculdade de Direito da UFMG. Diretor da Revista Brasileira de Estudos Políticos

O artigo discute a fragilidade epistemológica da Ciência da Informação, a partir da adoção de um termo polissêmico, como objeto científico, e a similaridade dessa situação com o contexto da criação da Teoria Pura do Direito de Hans Kelsen. Após a apresentação de algumas definições sobre o objeto da Ciência da Informação, discutem-se alguns reflexos relacionados à identidade científica e à fundamentação teórica derivadas de um objeto polissêmico. Apresenta-se uma breve introdução à Teoria Pura do Direito e algumas reflexões sobre a possibilidade de uma Teoria Pura da Ciência da Informação.

Palavras-chave: Ciência da Informação; Ciência do Direito; Epistemologia; Objeto científico; Teoria Pura do Direito.

\footnotetext{
Este artigo corresponde à versão revisada do trabalho "Da possibilidade de uma Teoria Pura da Ciência da
} Informação", apresentado pelos autores no XIII ENANCIB, no Rio de Janeiro, em 30 de outubro de 2012. 


\title{
The possibility of a Pure Theory of Information Science: initial reflections between Information Science and the Science of Law
}

\begin{abstract}
The paper discusses theepistemological fragilityof Information Sciencefrom theadoption ofa polysemic termas a scientific object and the similarityof this situationwith thecontext of the creationof thePure Theory of Lawby HansKelsen.After presenting some definitionson the subjectof Information Scienceit discusses somereflectionsrelated to the scientific identity of Information Science and problems with a theoretical basisderived fromapolysemic term. A brief introduction to the Pure Theory of Law is presented and some thoughts on the possibility of a Pure Theory of Information Science are discussed.
\end{abstract}

Key-words: Information Science; Science of Law; Epistemology; Scientific object; Pure Theory of Law.

recebido 30.04.2012 Aceito em 10.12.2012

\section{Introdução}

\footnotetext{
"Ao apresentarmos um conhecimento como ciência, afirma Kant, há necessidade, primacialmente, de determinar com precisão o que o mesmo tem de próprio e o que o distingue de outro conhecimento" (Afonso Bertagnoli)".
}

De acordo com a definição de Barreto (2009), este trabalho enquadra-se na Proposta para o Programa de Indução de Pesquisas na área de Ciência da Informação, dentro do Núcleo Temático proposto sobre os "Estudos dos fundamentos da Ciência da Informação com vistas à consolidação da área e construção de bases teórico-conceituais e metodológicas que levem à identidade da área numa reflexão de natureza interdisciplinar", cujos objetivos são:

Estudar e desenvolver conceitos e modelos fundamentais para a Ciência da Informação; Desenvolver as bases teóricas para o estudo da informação como objeto da Ciência da Informação, nos seus diferentes contextos; Realizar pesquisas que investiguem a interdisciplinaridade da área nos aspectos teóricos e aplicativos; Estudar a história da Ciência da Informação no seu processo evolutivo como campo do 
conhecimento; e Investigar os impactos das tecnologias da informação nos conceitos e no arcabouço teórico da Ciência da Informação (BARRETO, 2009, p. 24-5, grifo nosso).

Cabe ressaltar que o ponto de reflexão fulcral, aqui proposto, consiste exatamente no problema da adoção de um termo polissêmico como objeto de uma Ciência e como isso foi trabalhado por Hans Kelsen na proposição de sua Teoria Pura do Direito.

O presente trabalho procura estabelecer uma reflexão um pouco diferente do que tem sido a ênfase da discussão epistemológica na Ciência da Informação - quando ela ocorre. Conforme González de Gómez (2001, p. 5), "nas sociedades contemporâneas observamos a redução dos espaços discursivos e institucionais da epistemologia" e, especificamente em relação à Ciência da Informação, ela afirma que "a constituição de um campo científico da ciência da informação sempre foi uma questão em aberto". De acordo com Kobashi, Smit e Tálamo (2001), "a racionalidade técnica que, enquanto tal, é circunstancial e histórica, não foi substituída pela racionalidade acadêmico-reflexiva, fundamental para a institucionalização da identidade do campo." Na opinião das autoras, "não se encontra facilmente, por sua vez, a reflexão disciplinar objetivamente relacionada à constituição do seu objeto teórico [da Ciência da Informação]".

Nas palavras de Kobashi, Smit e Tálamo (2001), este trabalho busca uma contribuição à reflexão sobre a "passagem de uma situação précientífica, caracterizada pela utilização de significantes não associados a significados explicitados, para uma fase científica na qual os significantes têm significados explicitados e, portanto, avaliáveis". Sem um corpo teórico nítido, bem delimitado, que permita a visão clara do objeto comungado pelos diversos trabalhos produzidos, a área permanece frágil para integrar-se às outras disciplinas - em sua tão defendida e necessária interdisciplinaridade. Nesse sentido, as autoras argumentam que "sob a égide da interdisciplinaridade, o campo da informação se vê refletido em quadros teóricos de campos de conhecimento institucionalizados, submetendo-se à imposição de critérios disciplinares estranhos e nem sempre adequados aos seus objetivos específicos".

As autoras ainda afirmam que "a Ciência da Informação é um campo científico em constituição que não apresenta consenso quanto ao seu objeto, delimitação ou métodos". Em outro trabalho (KOBASHI; SMIT; TÁLAMO, 2004), elas firmam que "o levantamento terminológico fornece uma base sólida para concluir que os conceitos da área são insuficientes para que se possa deduzir dos mesmos uma delimitação teórica do objeto da área".

Situação similar pode ser observada em outra Ciência Social Aplicada, a Ciência do Direito, que apresenta uma rica discussão em relação ao seu objeto de estudo: assim como "informação", "direito" também é um termo de uso corrente que assume significados diversos em várias esferas da sociedade, inclusive no campo científico. 
Herbert Lionel Adolphus Hart, proeminente pensador do direito, é o autor de uma das obras que goza de mais prestígio entre os apreciadores da Filosofia do Direito e da Teoria Geral do Direito: "O conceito de direito", de 1961. A respeito desse livro, os editores comentam que...

[...] decorridos alguns anos desde a sua publicação, 0 Conceito de Direito transformou o modo como era compreendida e estudada a Teoria Geral do Direito no mundo de língua inglesa e fora dele. O seu enorme impacto deu origem a uma multiplicidade de publicações que discutem o livro e suas doutrinas, e isso não só no contexto da Teoria Jurídica, como também no da Filosofia Política e da Filosofia Moral (HART, 2007, nota dos editores).

O autor descreve alguns problemas concernentes à polissemia do termo "direito" e reflete sobre as suas implicações, afirmando que:

Poucas questões respeitantes à sociedade humana têm sido postas com tanta persistência e têm obtido respostas, por parte de pensadores sérios, de formas tão numerosas, variadas, estranhas e até paradoxais como a questão $<<0$ que é o direto? $>>$. Mesmo se limitarmos a nossa atenção à teoria jurídica dos últimos 150 anos e deixarmos de lado a especulação clássica e medieval acerca da $<<$ natureza $>>$ do direito, encontraremos uma situação sem paralelo em qualquer outra matéria estudada de forma sistemática como disciplina acadêmica autônoma (HART, 2007, p. 5, grifo nosso).

Ele também esclarece que, em parte, o sucesso de uma definição...

[...] depende de condições que frequentemente não estão preenchidas. A principal entre essas últimas é que devia haver uma família mais extensa de coisas ou genus, relativamente a cuja natureza estamos esclarecidos e dentro da qual a definição localiza o que define; porque, claramente, uma definição que nos diz que algo é membro de uma família não nos pode ajudar, se tivermos apenas ideias vagas ou confusas quanto à natureza da família. É esta exigência que, no caso do direito, torna inútil esta forma de definição, porque aqui não há uma categoria geral bem conhecida e familiar, de que o direito seja membro (HART, 2007, p. 19, grifo nosso).

Matos (2005, p. 13-14, grifo nosso) afirma que, conforme Simone Goyard-Fabre, o termo "direito" não é unívoco e a enorme confusão derivada dessa polissemia é causada pela "interpenetração de outras ciências no campo jurídico, sendo que as mesmas o ameaçam de absorção ou esmagamento, embaçando seu conceito". 
É possível a observação de que o termo "informação" apresenta grande similaridade com os problemas identificados para 0 termo "direito": ideias vagas ou confusas a respeito da natureza da "família", citada por Hart, e a interpenetração de outras ciências que ameaçam ou embaçam o seu conceito.

Dessa forma, compreender o tratamento dado pela Ciência do Direito ao problema pode contribuir para a reflexão epistemológica da Ciência da Informação e entre as principais tentativas de sistematização do corpo teórico da Ciência do Direito, a Teoria Pura do Direito de Hans Kelsen, talvez seja a mais debatida e criticada ${ }^{2}$. É essa a teoria do Direito a ser discutida adiante. É importante ressaltar que interessa ao desenvolvimento deste trabalho não a aplicação direta da Teoria Pura do Direito, mas a análise inicial do contexto de sua criação e a identificação de pontos convergentes com a situação discutida sobre a Ciência da Informação.

\section{Reflexões sobre o objeto da Ciênciada Informação}

A Associação Nacional de Pesquisa e Pós-Graduação em Ciência da Informação (ANCIB) define ${ }^{3}$ como objeto de estudo da área a informação. $\mathrm{Na}$ maior parte dos textos consultados da literatura específica da área, entretanto, sempre a informação está cercada de um contexto: a informação produzida, ou armazenada, ou o fluxo de informações, os serviços de informações, usuários de informações... Floridi (2002, p. 44, tradução do autor) afirma que conceitos polissêmicos - a exemplo de "informação" - somente podem ser bem investigados em relação a um contexto de uso bem definido. Brookes (1980, p. 126, tradução do autor), após explicitar a dificuldade sobre a conceituação da informação, afirma que é "difícil observarfenômenosde informação de forma isolada com o tipo dedesprendimento quea pesquisa científicatradicionalmentedemanda". Enfim, será que o objeto é realmente a informação ou toda uma dinâmica que ocorre em torno de um termo comum pressuposto que sempre aparece?

Um exemplo importante sobre essa discussão pode ser observado a partir da reflexão sobre as definições dos Grupos de Trabalho da ANCIB, coletadas em seu site ${ }^{4}$, durante o desenvolvimento deste trabalho. Os Grupos de Trabalho (GTs) são apresentados no Quadro 1, a seguir:

Cabe ressaltar que Hans Kelsen é amplamente reconhecido como um dos maiores juristas do século XX (MATOS, 2005, p.42-57), e assim como diversos outros autores e teorias não integra parte representativa dos cursos de Graduação em Direito, que se limitam a análises rápidas e superficiais de sua obra. Não se aplica, nesse caso, a simples e ingênua noção de que um autor não discutido em um curso de Graduação não é representativo ou importante para a sua área de conhecimento.

3 Conforme definição do seu Grupo de Trabalho 1: "Estudos Históricos e Epistemológicos da Ciência da Informação". Disponível em http://www.ancib.org.br/pages/grupos-de-trabalho/gt-1.php. Acesso em 20 abril 2012.

4 Disponível em http://www.ancib.org.br/pages/grupos-de-trabalho.php. Acesso em 20 abril 2012. 
Quadro 1 - Grupos de Trabalho da ANCIB

\begin{tabular}{cl}
\hline Grupo & Nome \\
\hline GT 1 & Estudos Históricos e Epistemológicos da Ciência da Informação \\
GT 2 & Organização e Representação do Conhecimento \\
GT 3 & Mediação, Circulação e Apropriação da Informação \\
GT 4 & Gestão da Informação e do Conhecimento nas Organizações \\
GT 5 & Política e Economia da Informação \\
GT 6 & Informação, Educação e Trabalho \\
GT 7 & Produçâo e Comunicação da Informação em CT\&I \\
GT 8 & Informação e Tennologia \\
GT 9 & Museu, Patrimônio e Informação \\
GT 10 & Informação e Memória \\
\hline
\end{tabular}

Fonte: Desenvolvido pelos autores

O mesmo site apresenta a definição de cada um desses Grupos de Trabalho. Não se questionam, em hipótese alguma, essas definições. Mas é possível observar, a partir do problema levantado sobre a conceituação do termo "informação", que existem definições sobrepostas e que alguns trabalhos podem ser desenvolvidos em dois ou mais Grupos de Trabalho ${ }^{5}$. Por exemplo, um trabalho que envolva um processo para a criação automática de uma base de citações de teses e dissertações apresentadas a um Programa de Pós-graduação poderia ser apresentado nos grupos:

GT2: Compreende, também, os estudos relacionados aos processos, produtos e instrumentos de representação do conhecimento (aqui, incluindo o uso das tecnologias da informação);

GT7: Inclui análises e desenvolvimento de métodos e técnicas, tais como bibliometria, cientometria, informetria, webometria, análise de rede e outros, assim como indicadores em CT\&I; e

GT8: Estudos e pesquisas teórico-práticos sobre e para o desenvolvimento de tecnologias de informação e comunicação, que envolvam os processos de geração, representação, armazenamento, recuperação, disseminação, uso, gestão, segurança e preservação da informação em ambientes digitais.

O Quadro 2 apresenta as definições completas dos GTs:

\footnotetext{
${ }^{5}$ Esse foi, inclusive, um debate levantado por alguns GTs na reunião de encerramento do XII ENANCIB, em
} 2011: a necessidade de revisão dessas definições. 


\section{Quadro 2 - Grupos de Trabalho da ANCIB e suas definições}

Grupo Definição

Estudos Históricos e Epistemológicos da Ciência da Informação. Constituição do campo científico e

GT 1 questões epistemológicas e históricas da Ciência da informação e seu objeto de estudo - a informação. Reflexões e discussões sobre a disciplinaridade, interdisciplinaridade e transdisciplinaridade, assim como a construção do conhecimento na área; Teorias, metodologias e práticas relacionadas à organização e preservação de documentos e da informação, enquanto conhecimento registrado e socializado, em ambiências informacionais tais

GT 2 como: arquivos, museus, bibliotecas e congêneres. Compreende, também, os estudos relacionados aos processos, produtos e instrumentos de representação do conhecimento (aqui, incluindo o uso das tecnologias da informação) e as relações inter e transdisciplinares neles verificadas, além de aspectos relacionados às políticas de organização e preservação da memória institucional;

Estudo dos processos e das relações entre mediação, circulação e apropriação de informações, em diferentes contextos e tempos históricos, considerados em sua complexidade, dinamismo e

GT 3 abrangência, bem como relacionados à construção e ao avanço do campo científico da Ciência da Informação, compreendido em dimensões inter e transdisciplinares, envolvendo múltiplos saberes e temáticas, bem com contribuições teórico-metodológicas diversificadas em sua constituição; Gestão da informação, de sistemas, de unidades, de serviços, de produtos e de recursos informacionais. Estudos de fluxos, processos e uso da informação na perspectiva da gestão.

GT 4 Metodologias de estudos de usuários. Monitoramento ambiental e inteligência competitiva no contexto da Ciência da Informação. Redes organizacionais: estudo, análise e avaliação para a gestão. Gestão do conhecimento e aprendizagem organizacional no contexto da Ciência da Informação. Tecnologias de Informação e comunicação aplicadas à gestão; Políticas de informação e suas expressões em diferentes campos. Sociedade da informação.

GT 5 Informação, Estado e governo. Propriedade intelectual. Acesso à informação. Economia política da informação e da comunicação; produção colaborativa. Informação, conhecimento e inovação. Inclusão informacional e inclusão digital;

Campo de trabalho informacional: atores, cenários, competências e habilidades requeridas. Organização, processos e relações de trabalho em unidades de informação. Sociedade do

GT 6 Conhecimento, tecnologia e trabalho. Saúde, mercado de trabalho e ética nas profissões da informação. Perfis de educação no campo informacional. Formação profissional: limites, campos disciplinares envolvidos, paradigmas educacionais predominantes e estudo comparado de modelos curriculares. O trabalho informacional como campo de pesquisas: abordagens e metodologias; Medição, mapeamento, diagnóstico e avaliação da informação nos processos de produção,

GT 7 armazenamento, comunicação e uso, em ciência, tecnologia e inovação. Inclui análises e desenvolvimento de métodos e técnicas tais como bibliometria, cientometria, informetria, webometria, análise de rede e outros, assim como indicadores em CT\&I;

Estudos e pesquisas teórico-práticos sobre e para o desenvolvimento de tecnologias de informação e

GT 8 comunicação que envolvam os processos de geração, representação, armazenamento, recuperação, disseminação, uso, gestão, segurança e preservação da informação em ambientes digitais; Análise das relações entre o Museu (fenômeno cultural), o Patrimônio (valor simbólico) e a

GT 9 Informação (processo), sob múltiplas perspectivas teóricas e práticas de análise. Museu, patrimônio e informação: interações e representações. Patrimônio musealizado: aspectos informacionais e comunicacionais;e

Estudos sobre a relação entre os campos de conhecimento da Ciência da Informação e da Memória Social. Pesquisas transdisciplinares que envolvem conceitos, teorias e práticas do binômio

GT 10 'informação e memória'. Memória coletiva, coleções e colecionismo, discurso e memória. Representações sociais e conhecimento. Articulação entre arte, cultura, tecnologia, informação e memória, através de seus referenciais, na contemporaneidade. Preservação e virtualização da memória social.

Fonte: Desenvolvido pelos autores.

O termo "informação" pode assumir várias definições ou interpretações que dependem do contexto: cada trabalho produzido utiliza uma dessas definições, justifica-se nesse determinado contexto e inserese na área. $\mathrm{E}$, de acordo com a definição adotada, fica claro que ele pertence à área - o trabalho, em si, é coerente. Mas múltiplas definições 
(nos diversos trabalhos) não podem significar, em certo sentido, múltiplos objetos com um nome comum? O objeto de uma ciência pode ser redefinido a cada trabalho? Em caso positivo, como é possível o diálogo entre tais trabalhos, que não partem de premissas compartilhadas, elemento fundamental da noção de ciência? Esse objeto ambíguo não torna frágil a Ciência da Informação? Como avaliar as contribuições para a área, se cada trabalho for coerente a partir de uma definição diferente adotada para o termo "informação"? Cada vez mais não seria reforçada a fragmentação, a dispersão, a não convergência? Como ser interdisciplinar, justificar-se interdisciplinar, se antes não se consolidar intradisciplinar?

É claro que a evolução da área é nítida, mas, talvez, aquém do que poderia ser, simplesmente porque o que amarra a produção em Ciência da Informação - o que existe de comum em grande parte dos trabalhos - é um nome: informação (ZINS, 2006). E, de certa forma, definições divergentes do termo justificam conflitos internos que chegam ao ponto de pretender a exclusão de determinados trabalhos da área. Esse desconforto com a (in)definição de seu objeto levanta a possibilidade de identificação de diversos domínios de conhecimento (às vezes mutuamente excludentes) - o que pode comprometer a própria noção de Ciência.

Não bastasse a confusão gerada a partir da polissemia do termo "informação", inúmeros trabalhos ainda se ocupam da combinação fatorial de expressões como "dado", "conhecimento", "mensagem", "saber" chegando até mesmo à proposição de alteração do nome de Ciência da Informação para "Ciência do Conhecimento" (ZINS, 2006), o que certamente aprofundaria ainda mais o caos conceitual, eis que a troca de um termo específico já problemático por outro genérico de maior alcance tende apenas a tornar mais distantes as vias de consenso epistemológico. Não pode ser negada a importância dos trabalhos da área, em hipótese alguma, mas isso acrescenta algum passo adiante na discussão epistemológica?

Reiterando a necessidade de definições mais claras na Ciência da Informação, são apresentados, a seguir, alguns conceitos encontrados na literatura consultada. Para Rendón Rojas (2008, p.72), "el objeto de estudio de la bibliotecología es el sistema informativo documental (SID) formado por la interacción entre información, documento, usuario e institución informativa documental". De acordo com Karamuftuoglu (2009), "Ciência da Informação é comumente associada ao estudo da coleta, classificação, armazenamento, recuperação e uso da informação. No entanto, não há consenso sobre o que é 'informação'" (KARAMUFTUOGLU, 2009, p. 2019, grifo nosso, tradução do autor).

Barreto (2009, p. 11) afirma que:

O objeto de estudo da CI é um constante construir de princípios e práticas relacionados com: a criação da informação como ação humana de dar existência ao que não existia antes e, depois, sua distribuição com a intenção de 
atingir universos simbólicos compatíveis com a geração de conhecimento.

Pinheiro (2004) aponta a informação como o objeto da CI, enquanto González de Gómez (1990, p. 121) afirma que seu objeto não seria a informação, mas sim "um conjunto de regras e relações tecidas entre agentes, processos e produções simbólicas e materiais.". Para ela, o domínio da CI não seria "a qualidade de um campo de fenômenos de informação (informação científica, informação tecnológica, informação para a cidadania)", mas um "ponto de vista que recorre a uma ampla zona transdisciplinar, com dimensões físicas comunicacionais, cognitivas e sociais ou antropológicas.". Saldanha (2008, p. 46-7) enxerga "a necessidade de ampliação dos estudos epistemológicos da informação, reconhecendo, a partir de diferentes proposições, a informação como uma construção social, de natureza dinâmica e contextual.".

Mas, mesmo em um contexto de confusão terminológica e desenvolvimento acelerado de tecnologias, se todos os trabalhos da área - mesmo adotando definições diferentes para seu objeto científico pertencem à Ciência da Informação, não existiria um "fator convergente", um "elo invisível", uma "estrutura flexível" anterior à própria noção de informação (seja ela qual for) e que permeia todos esses trabalhos, conferindo a unidade científica da área? Retirado o foco da "informação" e de seus correlatos "conhecimento", "dado", etc. - não seria possível uma reflexão epistemológica diferente para a área?

\section{A fragilidade de um objeto polissêmico}

Diversos autores - entre eles Araújo (2010); Araújo et al. (2007); Barbosa et al. (2000); Barreto (2009); Black (2006); Brookes (1980); Capurro e Hjorland (2003); Cornelius (2002); Floridi (2002); González de Gómez (1990; 2001); Jones (2010); Karamuftuoglu (2009); Kobashi; Smit e Tálamo (2001; 2004); Pinheiro (2004); Rabello (2012); Rendón Rojas (2008); Saldanha (2008); Silva (2006); Souza e Almeida (2009); Webber (2003) e Zins (2006; 2007a; 2007b; 2007c; 2007d) - discutem a definição e alguns conceitos relacionados à Ciência da Informação. São inúmeros os trabalhos que discutem o conceito de informação - "algumas vezes semelhantes, outras vezes sobrepostos e, em alguns casos, discordantes" (ARAUJO, 2009, p. 193) - e o único consenso parece ser o de que todo trabalho produzido deve escolher uma dessas definições para justificar-se enquanto produção da área. E o que os estudos da área possuem em comum, nas palavras do próprio Zins (2006), é um nome, que, não obstante, ganha sentidos muito diversos entre si.

O que se percebe, entretanto, é que, dessa forma, não será possível o avanço significativo de um corpo teórico da CI - tornando a área cada vez mais frágil. Isso porque o conhecimento desenvolvido a partir do conceito de informação adotado é válido, porém, a base conceitual em que repousam todos os trabalhos - a base conceitual comum da Ciência da Informação - é frágil. 
Rabello (2012) apresenta uma análise dos "mirantes de onde são observados e projetados os discursos que intentam, de alguma forma, minimizar a referida crise [de identidade]".O autor utilizou as epistemologias específica, particular e global de Hilton Japiassu para essa análise, concluindo que "as narrativas produzidas no campo têm sido direcionadas em espaços epistemológicos bem definidos, embora, por vezes, tenham tido uma trajetória transversal em sítios intermediários, proporcionando profícuos lugares de encontro epistemológicos". As conclusões do autor remetem, em resumo, a três espaços (específico, particular e global) e ainda a espaços intermediários possíveis entre eles ou seja, a Ciência da Informação continua sem a sua identidade.

Essa fragilidade é apontada por Kobashi, Smit e Tálamo (2004), para quem "a Ciência da Informação, na atual conjuntura, apresenta uma linguagem ainda muito próxima do senso comum e, portanto, pouco, ou insuficientemente, especializada", e, ainda, de acordo com as autoras:

A autonomização da linguagem de especialidade, afastando-a da linguagem natural, constitui um pressuposto para a constituição de qualquer campo científico e, portanto, igualmente, para a constituição da Ciência da Informação. Dito ainda em outros termos, nenhum campo científico se impõe no ambiente da pesquisa acadêmica se não dispuser de uma linguagem própria, ou seja, de uma linguagem especializada. E, para cumprir a função de uma linguagem especializada, esta pressupõe, por sua vez, que os termos da mesma remetam a conceitos específicos, distintivos.

Para Black (2006, p. 441, tradução do autor), "a tarefa de definir os termos que começam por 'informação' é sempre difícil, pois inevitavelmente levanta questões sobre a natureza e as propriedades da informação no contexto das relações humanas". Em suas conclusões, Cornelius (2002, p. 420) explicita a falta de uma teoria comum para a área como um problema estrutural ${ }^{6}$. Capurro e Hjorland (2003, p. 396) afirmam que é preciso clarear melhor a identidade e objetivos específicos da Ciência da Informação ${ }^{7}$ e que adotar uma ou outra definição para o termo "informação" é complicado, pois elas envolvem conceitos implícitos ou, às vezes, vagos. ${ }^{8}$

6The two main problems within information science are structural. First, a failure to establish the framework for information theory that will serve information science as a whole: It is as if we do not really need a theory of information.

7We should be aware that library and information science is only one discipline among a network of disciplines and metadisciplines dealing with communication, technology, systems, and related processes. We should try to further clarify our identity and our specific goals, and to strengthen historical continuity in the field. We should not consider the concept of information in isolation, but see it in relation to other concepts such as, for example, documents and media. The concept of information may indeed have had a positive effect as a status booster for professions primarily working with documents. However, this positive effect has had the unfortunate consequence of raising the level of confusion in the discipline. It is worth noting that important books can be written in the field.

8There are many concepts of information, and they are embedded in more or less explicit theoretical structures. In studying information it is easy to lose one's orientation. Therefore, it is important to state the pragmatic question: 'What difference does it make if we use one or another theory, or concept, of information?' This task is difficult because many approaches involve implicit or vague concepts, which must be clarified. (Such a clarification may provoke resistance because information is so often used as a status- 
De acordo com Kobashi, Smit e Tálamo (2004) "a Ciência da Informação é um campo científico em constituição. Assim como não há opiniões contrastantes quanto a esta afirmação, tampouco se pode afirmar que exista consenso quanto ao seu objeto e campo abrangido." As autoras também afirmam que (KOBASHI; SMIT; TÁLAMO, 2001), "na ausência de um assentamento conceitual ou na presença de ambivalências semânticas, que poderiam supostamente estabelecer condições de criação, tem-se um impasse ou retardamento teórico, que compromete a área como um todo." Silva (2006, p. 115) destaca que "não há um corpus teórico-metodológico específico. A CI ainda está tão porosa que não existe, no fundo, como ciência, sob o ponto de vista teórico". A seguir, o autor tece comentários sobre a abordagem pós-moderna da $\mathrm{CI}$, que não define um objeto específico e que ele considera interessante "mas ao mesmo tempo perigosa, porque esquecemos que estamos a falar de uma área que queremos assumir como científica, mas que não estamos a contribuir para a consolidar do ponto de vista do paradigma".

Ao explicar alguns problemas na interpretação das categorias usadas para classificar a Ciência da Informação em sua pesquisa - ciência social, ciência interdisciplinar, ciência pós-moderna, e sua relação com a Biblioteconomia - Araújo et al. (2007, p. 107) apontam para a falta de consenso na definição de uma base conceitual da área:

Parte da resposta a isso se deve ao pouco tempo de existência da área, que vem sendo construída nas últimas décadas por pesquisadores oriundos de diferentes áreas e também de diferentes campos teóricos. Isso se evidencia de forma muito clara quando se observa o resultado das questões que solicitavam a indicação de autores e obras relevantes. Ao contrário de ciências bem consolidadas, nas quais há grande consenso sobre os "clássicos", os fundadores, as obras fundamentais, na CI a dispersão é gigantesca: há casos em que entre os dez autores listados por um professor não havia um coincidente com a lista de dez de outro professor, mesmo quando ambos pertenciam a uma mesma instituição.

Essa fragilidade da CI é abordada por alguns autores, entre eles Souza e Almeida (2009, p. 158). Os autores analisam uma clássica definição da CI, de Borko", e concluem que "não é motivo de celeuma que, com tal definição, virtualmente quaisquer dos objetos de pesquisa acadêmica na atualidade envolva algum componente ligado à Ciência da Informação". Os autores enfatizam uma área específica da CI, a representação da informação, e justificam-na - de forma parcial, assumida pelos próprios - como a área fulcral da CI. Em seguida, esses autores afirmam que alguns dos pontos de contato da CI com outras

BORKO, H. Information Science: What is it? American Documentation, v. 19, p. 3-5, Jan. 1968. 
disciplinas "contribuem para a difusão das suas fronteiras e a dissolução de sua identidade" (SOUZA; ALMEIDA, 2009, p. 160). A solução proposta pelos autores é apresentada da seguinte forma: "para distinguir aquilo que é pertinente, e o que se afasta da identidade científica nuclear, há que se delinear as linhas de corte".

Mas não existe uma grande nebulosidade justamente na definição de tal identidade científica nuclear - qual é o objeto de pesquisa da CI? Em nossa opinião - também em forma de provocação à reflexão - Souza e Almeida (2009) trazem à tona um ponto importante de discussão, porém tratam da periferia do problema e não de seu núcleo estruturante. O problema não está nas linhas de corte, mas na definição clara dessa identidade nuclear - e somente a partir disso é que os critérios para o estabelecimento de "linhas de corte" serão mais nítidos. Nesse sentido apontam Kobashi, Smit e Tálamo (2001), para quem as expressões de outras áreas vizinhas "poderão ser analisadas e dimensionadas suas funções em relação ao objeto da área". Conforme as autoras, um cenário classificado como pós-moderno exige conceituações e discussões de objetos científicos e, no caso específico, a discussão do objeto da CI e a identificação dos limites com outras áreas do conhecimento. Kobashi, Smit e Tálamo (2004) apontam ainda que "a área, seja qual for a designação a ela atribuída, afirmou-se na interdisciplinaridade, seguindo o modo de constituição da ciência proposto pela pós-modernidade, sem examinar com clareza sua própria trajetória disciplinar autônoma".

Rendón Rojas (2008) também discute a questão da identidade científica ao justificar a importância do estudo epistemológico para a área:

(1) Para lograr un autoconocimiento de la disciplina; esto es, para encontrar la identidad de la ciencia bibliotecológica y de la información, y para construir un metarrelato de la teoría de la información que especifique su ser, su hacer y su valer ante sí, ante otras ciencias y ante la sociedad. Esta tarea requiere un estudio sistemático y permanente. (2) Para autoconstruirse; esto es, para fundamentar su cuerpo teórico y huir de las modas cambiantes en terminologia, y para crear un cuerpo conceptual propio preciso, claro y definido. (3) Para desarrollar la interdisciplinar; esto es, para entrar en diálogo e interrelación con otras disciplinas pero con plena identidad, lo que le permitirá evitar la tentación de invadir otros campos de conocimiento y al mismo tiempo le impedirá ser absorbida por otras ciencias (RENDÓN ROJAS, 2008, p. 66-7, grifo nosso).

Com o intuito de definir a identidade científica da Ciência da Informação, o autor (RENDÓN ROJAS, 2008, p.71-5) recorre aos Programas de Investigação Científica de Imre Lakatos ${ }^{10}$. Em seguida, ele

\footnotetext{
${ }^{10}$ Cada PIC [Programa de Investigación Científica] está compuesto por un núcleo central que le da identidad, un cinturón protector formado por diferentes teorías que pueden ir cambiando, desapareciendo o apareciendo, y una heurística que nos indica lo que se debe hacer y no se debe hacer. De acuerdo con este planteamiento, el núcleo central nos permite resguardar la tradición científica, mientras que el cinturón protector nos da la
} 
define as principais categorias do núcleo central do Programa de Pesquisa Científica da Ciência da Informação: informação, documento, usuário, instituição informativa documental e o profissional da informação documental. A partir desse núcleo, são apresentadas algumas possibilidades de relacionamento interdisciplinar para a Ciência da Informação.

Brookes (1980, p. 125, tradução do autor) afirma que a "ciência da informação flutua em um limbo filosófico. Ela não tem fundamentos teóricos". Floridi (2002) afirma que a Epistemologia Social não pode ser considerada a base filosófica da Ciência da Informação e propõe a Filosofia da Informação como essa base - a Ciência da Informação, para o autor, seria uma aplicação prática da Filosofia da Informação.

Webber (2003, p. 311-28) apresenta alguns questionamentos iniciais importantes em seu artigo sobre a Ciência da Informação, particularmente no Reino Unido: ela ainda é uma disciplina viva, considerando-se, também, que a associação profissional (Instituto de Cientistas da Informação) fechou suas portas em 2002? A Ciência da Informação é, afinal, uma disciplina? A autora justifica a discussão sobre o significado do termo "informação", pois a maneira como ele é interpretado tem influência direta no escopo e limites da disciplina. Ela aponta como uma de suas conclusões que a Ciência da Informação é uma disciplina válida e importante, mesmo sem uma grande teoria unificadora, e que "parecefundamental que os envolvidos em suas especialidades continuem a ver seus esforços como parte de um todo interligado, para que juntos possam trabalhar para trazer a visão que os pioneiros da ciência da informação traçaram" (tradução do autor).

\section{A Teoria Purado Direito de Hans Kelsen}

"Há mais de duas décadas que empreendi desenvolver uma teoria jurídica pura, isto é, purificada de toda a ideologia política e de todos os elementos de ciência natural, uma teoria jurídica consciente da sua especificidade porque consciente da legalidade específica do seu objeto. [...] Importava explicar, não as suas tendências endereçadas à formação do Direito, mas as suas tendências exclusivamente dirigidas ao conhecimento do Direito, e aproximar tanto quanto possível os seus

posibilidad de tener la innovación. Sin embargo hacemos la precisión de que el núcleo central se toma no por consenso, sino porque contiene enunciados verdaderos y conceptos adecuados, y porque permite conocer la realidad que pretende estudiar. Asimismo afirmamos que ese núcleo central no es inmutable, porque que se puede profundizar em él, com lo cual lo que se consideraba parte integrante de él pasaría a formar parte del cinturón protector. 
resultados do ideal de toda a ciência: objetividade e exatidão" (Hans Kelsen).

Hans Kelsen, um dos grandes juristas do século XX, publicou cerca de quatrocentos livros e artigos - também sobre filosofia, sociologia, religião, antropologia e política - com destaque para a "Teoria Pura do Direito", dada a difusão e influência alcançada. Nessa obra, gestada de 1911 a 1960, compreendendo praticamente toda a carreira acadêmica de Kelsen, o autor propôs um objeto de estudo - a norma - e uma metodologia própria - o método normológico - para a então "indefinida" Ciência do Direito.

É importante destacar a vinculação de Kelsen ao positivismo jurídico, que não apresenta relação com o positivismo sociológico de Comte, de origem francesa, de acordo com Bobbio (1995, p. 15): "o primeiro [o positivismo jurídico] surge na Alemanha, o segundo surge na França. A expressão 'positivismo jurídico' deriva da locução direito positivo contraposta àquela de direito natural." O autor também ressalta que:

O positivismo jurídico nasce do esforço de transformar o estudo do direito numa verdadeira e adequada ciência que tivesse as mesmas características das ciências físicomatemáticas, naturais e sociais. Ora, a característica fundamental da ciência consiste em sua avaloratividade, isto é, na distinção entre juízos de fato e juízos de valor e na rigorosa exclusão destes últimos do campo científico: a ciência consiste somente em juízos de fato. O motivo dessa distinção e dessa exclusão reside na natureza diversa desses dois tipos de juízo: o juízo de fato representa uma tomada de conhecimento da realidade, visto que a formulação de tal juízo tem apenas a finalidade de informar, de comunicar a um outro a minha constatação; o juízo de valor representa, ao contrário, uma tomada de posição frente à realidade, visto que sua formulação possui a finalidade não de informar, mas de influir sobre o outro, isto é, de fazer com que o outro realize uma escolha igual à minha e, eventualmente, siga certas prescrições minhas. [...] A ciência exclui do próprio âmbito os juízos de valor, porque ela deseja ser um conhecimento puramente objetivo da realidade, enquanto os juízos em questão são sempre subjetivos (ou pessoais) e consequentemente contrários à exigência de objetividade. ( $p$. 135, grifo nosso).

Kelsen não pretendia isolar o Direito das outras áreas e foi claro ao estabelecer como princípio metodológico fundamental a retirada dos elementos estranhos ao Direito. Para tanto, é preciso compreender que Kelsen compreende o Direito - com maiúscula - como a ciência que 
estuda certo objeto, qual seja, o direito - com minúscula - que se mostra enquanto ordenamento jurídico. Dessa forma, o Direito se compõe não de normas, que são seu objeto, mas, sim, de proposições jurídicas, conformando uma verdadeira metalinguagem. A designação "pura", conforme o autor, "significa que ela se propõe a garantir um conhecimento apenas dirigido ao Direito e excluir desse conhecimento tudo quanto não pertença ao seu objeto, tudo quanto não possa, rigorosamente, determinar como Direito" (KELSEN, 2006, p. 1).

De acordo com Matos (2005, p. 91, grifo nosso),

[...] a opção metodológica kelseniana pressupõe pelo menos três condições: [uma delas, a] delimitação rigorosa do campo de estudos: o objeto a ser conhecido não pode ser comum a outras investigações científicas. Se é verdade que várias disciplinas ou ciências podem estudar o mesmo objeto, i.e., podem ter o mesmo objeto material, é certo também que cada uma delas deve abordá-lo de forma específica, constituindo assim seu objeto formal. É essa especial maneira de estudar e visualizar o objeto que diferencia cada uma das ciências, sendo que tal condição já é exigida por Kant.

Ainda conforme Matos (2005, p. 40-41), "Weber afirma que os campos da ciência e da política devem permanecer separados, porque a ciência não tem a função de valorar a realidade, devendo apenas conhecêla por meio de um ponto de vista objetivo". Para o autor, Kelsen desenvolve seu conceito de ciência pura a partir desse ponto de vista:

Um saber racional que não se ocupa de valores e de conteúdos no sentido de impor ou aconselhar sua observância. Em diversas oportunidades, Kelsen afirmou que servia à verdade e não ao poder político. A escravidão do espírito que seduziu a muitos e cujo nome não é outro senão "ideologia" foi incapaz de cegá-lo. Preferindo a neutralidade axiológica à defesa intransigente e dogmática de um valor tido por absoluto em detrimento de todos os outros, Kelsen se manteve fiel ao seu propósito de serviçal do saber. Tal posição - que não é uma ideologia, mas antes um pressuposto epistemológico - deu origem às mais ferozes críticas que foram dirigidas à Teoria Pura do Direito.

Para Kelsen, a natureza pode ser considerada "uma determinada ordem das coisas ou um sistema de elementos que estão ligados [...] segundo um princípo que designamos por causalidade" (KELSEN, 2006, p. 85). Esse princípio, para ele, é a base das leis que descrevem os objetos das ciências naturais. Nesse sentido, se a conduta humana for considerada um elemento da natureza analisado a partir desse princípio, não há razão suficiente para separar as ciências naturais das sociais. Kelsen explica que adistinção de uma ciência social - no caso em tela, o 
Direito - somente será possível caso as conexões dos atos de conduta humana sejam descritos por outro princípio ordenador que não o da causalidade. Designado pelo autor como princípio da imputação, ele difere do da causalidade na medida em que a relação entre dois elementos se dá não por uma questão da natureza, mas por um ato de vontade do homem. Enquanto nas ciências naturais a relação é definida por ser (quando é $A, B$ também é ou será, necessariamente), o princípio da imputação é regido pelo dever ser (quando A é, B deve ser). Ademais, o princípio da causalidade não encontra ponto terminal, eis que o efeito de dado fenômeno pode ser tido como a causa de outro e assim sucessivamente. Ao contrário, o princípio da imputação se exerce mediante uma radical definição de seu terminus, não dando lugar a cadeias infinitas de causalidade, dado que o que está em questão é um juízo normativo humano e não um dado causal natural.

Qual seria o princípio ordenador da Ciência da Informação? Como a Ciência da Informação separa e relaciona seu objeto material - a realidade fenomênica sobre a qual se debruça - e seu objeto formal? Tenha-se em mente que o objeto formal é a especial forma com a qual se observa o objeto material, recortando a realidade para dela não apenas extrair um sentido, mas sim construir determinada área de interesse científico. Assim, se percebe, como Kelsen não se cansa de repetir, que o objeto formal não é naturalístico, mas sim algo criado pela ciência, que, como tal, é sempre um discurso de segunda ordem sobre a realidade (metalinguagem) autolegitimador, ainda que, no limite, não possa se autofundametar, exigindo o concurso do conhecimento filosófico. Essa e outras questões podem ser suscitadas pela reflexão, a partir dos trabalhos de Hans Kelsen, e acreditamos que o aprofundamento nessa discussão pode contribuir para a discussão epistemológica da Ciência da Informação.

\section{Conclusões}

As reflexões aqui delineadas - em torno de uma possível Teoria Pura da Ciência da Informação - visam uma contribuição em relação ao cenário observado a partir das conclusões apresentadas por Smit, Dias e Souza (2002, grifo nosso) sobre a Avaliação da CAPES de 2001 a respeito da Ciência da Informação:

A bem da verdade, a avaliação continuada da CAPES deixou uma preocupação em relação a uma área que não demonstra muita vitalidade, à qual faltam grandes idéias, grandes iniciativas, uma certa ousadia. A área ousa muito pouco: menos que o desejável, em todo caso. Esta é a sensação que permanece. Ou continuamos fazendo nossas pesquisas com uma visão muito imediatista e de aplicação local, e rapidamente seremos varridos do mapa das agências, ou começamos a fazer de fato uma ciência com $\mathrm{C}$ maiúsculo, que pode até se caracterizar por sua especificidade conquanto consigamos explicitar no que esta consiste. Caso contrário, se 
formos avaliados pelos critérios tradicionais da pesquisa, nossa fragilidade se manifestará rapidamente. Bastará inquirir quantas pesquisas produzidas pelos programas de pósgraduação em Ciência da Informação tendem a propor generalizações ou abstrações que ultrapassem o estágio da pesquisa empírica, dos relatos, das descrições e dos estudos de caso.

Kelsen ressentia-se exatamente de uma metodologia e objeto próprios do Direito - em suma, a explicitação de sua especificidade enquanto ciência (sob pena de o Direto se confundir com as demais ciências que ameaçavam anexá-lo no início do século $X X)$ - e foi essa a motivação essencial da criação de sua Teoria Pura. Para os propósitos deste trabalho, sua teoria foi brevemente introduzida como uma possibilidade concreta, a partir da qual pode ser desenvolvida uma relfexão epistemológica mais profunda na Ciência da Informação.

Floridi (2002) aponta a Filosofia da Informação como a base necessária à Ciência da Informação. Talvez, seja realmente esse o ponto fulcral a ser perseguido: qual a base filosófica em que repousa a Ciência da Informação? Mas, discutí-la como Filosofia da Informação - em contraponto à Filosofia do Conhecimento - não remeterá aos mesmos problemas - e, nesse caso, ainda mais profundos e insolúveis - de polissemia?...

\section{Referências}

ARAújO, C. A. A. Correntes teóricas da ciência da informação. Ciência da Informação, Brasília, v. 38, n. 3, p. 192-204, set./dez. 2009.

ARAÚJO, C. A. A. O conceito de informação na ciência da informação. Informação \& Sociedade, v. 20, n. 3, p. 95-105, 2010.

ARAÚJO, C. A. A. et al. A ciência da informação na visão dos professores e pesquisadores brasileiros. Inf. \&Soc.:Est., v. 17, n. 2, p. 95-108, maio/ago. 2007.

BARBOSA, R. R. et al. Novo nome e novo paradigma: da biblioteconomia à ciência da informação. Perspectivas em Ciência da Informação, Belo Horizonte, v. 5, n. esp., n. esp., jan./jun. 2000.

BARRETO, A. de A. Olhar sobre os 20 anos da associação nacional de pesquisa e pós-graduação em ciência da informação (ancib). Pesq. bras. Ci. Inf., Brasília, v. 2, n. 1, p. 3-28, jan./dez. 2009.

BLACK, A. Information history. Annual Review of Information Science and Technology, v. 40, p. 441-473, 2006.

BOBBIO, N. O positivismo jurídico: lições de filosofia do direito. São Paulo: Ícone, 1995. 
BROOKES, B. C. The foundations of information science: part I. Philosophical aspects. Journal of Information Science, v. 2, p. 125-133, 1980.

CAPURRO, R.; HJORLAND, B.The concept of information. Annual Review of Information science and Technology, v. 37, p. 343-411, 2003.

CORNELIUS, I. Theorizing information for information science. Annual Review of Information Science and Technology, v. 36, p. 392-425, 2002.

FLORIDI, L. Ondefininglibrary and information scienceas applied philosophy of information. Social Epistemology, v. 16, n. 1, p. 37-49, 2002.

GONZÁleZ DE GÓMEZ, M. N. O objeto de estudo da Ciência da Informação: paradoxos e desafios. Ciência da Informação, Brasília, v. 19, n. 2, jul./dez. 1990.

GONZÁLEZ DE GÓMEZ, M. N. Para uma reflexão epistemológica acerca da Ciência da Informação. Perspectivas em Ciência da Informação, Belo Horizonte, v. 6, n. 1, p. 5-18, jan./jun., 2001.

HART, H. L. A. Questões persistentes. In: HART, H. L. A. O conceito de direito. 5. ed. Lisboa: Fundação Calouste Gulbenkian, 2007.

JONES, W. No knowledge but through information. First Monday, Chicago, v. 15, n. 9, 2010.

KARAMUFTUOGLU, M. Situating logic and information in Information Science. Journal of the American Society for Information Science and Technology, v. 60, n. 10, p. 2019-2031, 2009.

KELSEN, H. Teoria pura do direito. 7. ed. São Paulo, Martins Fontes, 2006. KOBASHI, N. Y.; SMIT, J. W.; TÁLAMO, M. de F. G. M. A função da terminologia na construção do objeto da Ciência da Informação. DataGramaZero, Rio de Janeiro, v. 2, n. 2, abr. 2001. Disponível em: <http://www.dgz.org.br/abr01/Art_03.htm>. Acesso em: 20 fev. 2012.

KOBASHI, N. Y.; SMIT, J. W.; TÁLAMO, M. de F. G. M.. A determinação do campo científico da Ciência da Informação: uma abordagem terminológica. DataGramaZero, Rio de Janeiro, v. 5, n. 1, fev. 2004. Disponível em: < http://www.dgz.org.br/fev04/Art_03.htm >. Acesso em: 20 fev. 2012.

MATOS, A. S. de M. C. Filosofia do Direito e Justiça: na obra de Hans Kelsen. Belo Horizonte: Del Rey, 2005.

PINHEIRO, L. V. R. Informação esse obscuro objeto da Ciência da Informação. Morpheus, Rio de Janeiro, v. 2, n. 4, 2004. Disponível em: <http://www.unirio.br/morpheusonline/Numero04-2004/Ipinheiro.htm >. Acesso em: 20 fev. 2012. 
RABELLO, R. A Ciencia da Informacao como objeto: epistemologias como lugares de encontro. Perspectivas em Ciencia da Informacao, v. 17, n. 1, p. 2-36, jan./mar. 2012.

RENDÓN ROJAS, M. Á. La ciencia de la información en el contexto de las ciencias sociales y humanas. Ontología, epistemología, metodología e interdisciplina. Investigación Bibliotecológica, v. 22, n. 44, enero/abril 2008. <http://biblioteca.universia.net/html_bura/ficha/params/title/cienciabibliotecologica-informacion-contexto-ciencias-sociales-humanasepistemologia-metodologia-interdisciplina/id/44779823.html> .

Acesso em: 21 fev. 2012.

SALDANHA, G. S. Viagem aos becos e travessas da tradição pragmática da Ciência da Informação: uma leitura em diálogo com Wittgenstein. 2008. 337 f. Dissertação (Mestrado em Ciência da Informação) - Curso de Pós-Graduação em Ciência da Informação, Universidade Federal de Minas Gerais, Belo Horizonte, 2008.

SILVA, A. M. da. A informação: da compreensão do fenómeno e construção do objecto científico. Porto: Edições Afrontamento, 2006.

SMIT, J. W.; DIAS, E. W.; SOUZA, R. F. de. Contribuição da pósgraduação para a Ciência da Informação no Brasil: uma visão. DataGramaZero, v. 3, n. 6, dez. 2002. Disponível em: <http://www.dgz.org.br/dez02/Art_04.htm>. Acesso em: 21 fev. 2012.

SOUZA, R. R.; ALMEIDA, M. B. de. Representação do conhecimento: identidade ou esvaziamento da Ciência da informação? In: ENCONTRO IBÉRICO EDIBCIC, 4., 2009, Coimbra. Anais... Coimbra: Imprensa da Universidade de Coimbra, 2009. v. I. p. 157-166.

WEBBER, S. Information Science in 2003: a critique. Journal of Information Science, v. ? v. 29, n.4, p. 311-30, 2003.

ZINS, C. Redefining information science: from "information science" to "knowledge science". JournalofDocumentation, v. 62 n. 4, p. 447-461, 2006.

ZINS, C. Conceptions of Information Science. Journal of the American Society for Information Science and Technology, v. 58, n. 3, p. 335-350, $2007 a$.

ZINS, C. Conceptual approaches for defining 'data', 'information', and 'knowledge'. Journal of the American Society for Information Science and Technology, v. 58, n. 4, p. 479-493, 2007 b.

ZINS, C. Knowledge map of Information Science. Journal of the American Society for Information Science and Technology, v. 58, n. 4, p. 526-535, 2007c.

ZINS, C. Classification schemes of Information Science: twenty-eight scholars map the field. Journal of the American Society for Information Science and Technology, v. 58, n. 5, p. 645-672, 2007d. 